\title{
Cerium Oxide Nanoparticles as Novel Tool in Glioma Treatment: An In vitro Study
}

Sack-Zschauer $\mathbf{M}^{*}$, Bader S and Brenneisen P

Institute of Biochemistry and Molecular Biology I, Medical Faculty, Heinrich-Heine-University, Düsseldorf 40225, Germany

\begin{abstract}
The interaction between cancer cells and the stromal microenvironment is an important aspect in tumor progression and reflects a big challenge especially in context of an efficient treatment of brain tumors such as gliomas. An intensive crosstalk between glioma cells and stromal cells such as endothelial cells inter alia being part of the blood-brain barrier (BBB) often results in the occurrence of a relapse and poor prognosis. A complete resection of gliomas which are characterized by a high proliferation rate and invasiveness as well as extensive vascularization is not possible until yet and a post-operative care with existing therapies is crucial and often not as successful as expected. In that context, redox-active nanoparticles such as cerium oxide nanoparticles (CNP) are a promising tool and may solve some treatment problems closely associated with brain tumors. In this study, CNP have a cytotoxic effect on anaplastic astrocytoma (grade III glioma) cells while the same concentration shows no cytotoxicity on microvascular endothelial cells used as stromal cell model. However, the migration capacity of endothelial cells, their invasiveness and the formation of new blood capillaries is lowered as well as the expression and/or secretion of the angiogenesis marker EMMPRIN, being a positive aspect in anticancer therapies. These data are a first indication that CNP may have potential for an application in a therapy against malignant gliomas (grade III and IV glioma).
\end{abstract}

Keywords: Redox-active nanoparticles; Cerium oxide nanoparticles; Glioma; Tumor-stroma interactions; Anti-angiogenic therapy; Cancer; Neoangiogenesis; Endothelial cells

\section{Introduction}

It was shown by epidemiological studies that gliomas are the most common primary brain tumors in adults; among which the astrocytic glioma represents the largest subgroup [1,2]. Gliomas have a high tendency to invade rapidly into the surrounding brain tissue; to damage the blood-brain barrier; and to promote the formation of new blood vessels which is called neoangiogenesis and representing a major proportion of the tumor-stroma interactions during tumor progression [3-8]. According to the World Health Organization (WHO) classification; gliomas are classified spanning a spectrum from low to high grade and are graded pathologically on a scale of one to four [9]. High grade gliomas (grade III; IV) carry a poor prognosis; have a rather low median survival rate; and are known as anaplastic astrocytoma (grade III); oligoastrocytoma (grade III); oligodendroglioma (grade III); and glioblastoma (grade IV). Grade III and IV gliomas are rich in blood vessels (i.e. highly vascular) and in proteins such as extracellular matrix metalloproteinase inducer (EMMPRIN) and vascular endothelial growth factor (VEGF); both promoting neovascularization and invasion. The protein EMMPRIN; also known as CD147 or basigin; belongs to the immunoglobulin family of adhesion molecules and is a type I transmembrane glycoprotein [10]. Epidemiological studies show that EMMPRIN is overexpressed in about 67 to $86 \%$ of anaplastic astrocytoma and glioblastoma; therefore often used as negative prognostic factor for patients with astrocytic gliomas [11-13]. In addition to its occurrrence on the surface and as secreted form of tumor cells [14-16]; EMMPRIN expression was also described for endothelial cells [17-19] and was shown to have a broad range of functions. It is involved in induction and secretion of some types of matrix metalloproteinases (MMPs) [20,21]; controls glycolysis by regulating lactate export through the monocarboxylate carriers MCT1 and MCT4 [22,23]; and accelerates neovascularization by enhancing the level of VEGF; a critical stimulator of tumor angiogenesis; in cancer cells [24-26]. Traditional options to attack cancer cells comprise surgical procedure; radio- and/or chemotherapy; but often resulting in harmful effects on normal (healthy) cells and holding the risk of secondary cancers. Among the most effective antineoplastic agents are the anthracyclines such as doxorubicin; epirubicin and others; which are used for treatment of non-solid and solid tumors [27,28]. Among the severe side effects alopecia; vomiting; nausea; mucositis and cardiotoxicity are described; to name but a few. Furthermore; the occurrence of drug resistance is problematic as well [28]. Currently; the therapeutic options against gliomas mainly depend on different factors such as the tumor grade; the localization of the tumor mass; the Karnofyky performance status (KPS score); neurological deficits; and age of the patient [29] and primarily comprise the surgical effort of a "total" tumor resection followed by radiotherapy and/or chemotherapy $[30,31]$. As the high graded gliomas are characterized by fast proliferation and high invasiveness into the surrounding brain tissue; a complete resection is almost impossible. In many cases; a combination of radiotherapy and the use of chemotherapeutical drugs such as temozolomide [32-34] and/or bevacizumab [25,34-36] is the method of choice as postoperative procedure. In addition; the nanomedicine; reflecting the medical use of nanomaterials; shows some promising therapeutic approaches which are already in clinical trials [37,38]. In that context; nanoparticles (NPs) are mainly used as carrier to transport antitumor drugs to specific targets in the human body (nanocarriers). Currently; the development of actively targeted NPs having a positive impact on the physical interactions between the nanoparticles and the blood-brain barrier (BBB) cells and; thereby; facilitating the transit

*Corresponding author: Maren Sack-Zschauer, Institute of Biochemistry and Molecular Biology I, Medical Faculty, Heinrich-Heine-University, Düsseldorf 40225, Germany, Tel: 492118112835; E-mail: Maren.Sack@uni-duesseldorf.de

Received: December 05, 2017; Accepted: December 12, 2017; Published: December 18, 2017

Citation: Sack-Zschauer M, Bader S, Brenneisen P (2017) Cerium Oxide Nanoparticles as Novel Tool in Glioma Treatment: An In vitro Study. J Nanomed Nanotechnol 8: 474. doi: 10.4172/2157-7439.1000474

Copyright: () 2017 Sack-Zschauer M, et al. This is an open-access article distributed under the terms of the Creative Commons Attribution License, which permits unrestricted use, distribution, and reproduction in any medium, provided the original author and source are credited. 
across the BBB is a novel strategy against malignant gliomas $[3,39,40]$. Nevertheless; prior to a routine clinical use of these nanocarriers; there are still some unanswered questions which must be addressed. On the other hand; direct pharmacologically active nanoparticles are used in different medical approaches. In that context and due to their oxygen vacancies on the surface; cerium oxide $\left(\mathrm{CeO} / \mathrm{Ce}_{2} \mathrm{O}_{3}\right)$ nanoparticles (CNP; nanoceria) switching autocatalytically between the oxidation states IV $\left(\mathrm{Ce}^{4+}\right)$ and III $\left(\mathrm{Ce}^{3+}\right)$ function as pro- and antioxidants on the basis of the impact of the redox couple $\mathrm{Ce}^{4+} / \mathrm{Ce}^{3+}$ [41-44]. In this study; the question was addressed of whether cerium oxide nanoparticles have a similar bifunctional effect (pro- and antioxidant) on the human astrocytoma cell line (MOG-G-CCM); established from a grade III glioma; and on the microvascular endothelial cell line HMEC-1; representing a model of stromal (healthy) cells. HMEC-1 cells are often used as standard cell culture model for studies on tumor-stroma interactions as a replacement for primary human endothelial cells $[45,46]$. In this in vitro glioma-endothelial cell model; we demonstrate that cerium oxide nanoparticles kill anaplastic astrocytoma (grade III glioma) cells while the same concentration shows no cytotoxicity on endothelial cells; rather protecting these cells against tumor-supporting effects such as migration; invasion; and tube formation representing a simple model of neoangiogenesis.

\section{Materials and Methods}

The cell culture medium Dulbecco's modified Eagle medium (DMEM) was purchased from Invitrogen and the fetal calf serum from Pan Biotech. All chemicals were purchased from Sigma or Merck Biosciences; unless otherwise stated. The cerium oxide nanoparticles (water based suspension; $1.5 \mathrm{mg} / \mathrm{ml}(8.7 \mathrm{mM}) ; 1-10 \mathrm{~nm}$ diameter) were purchased by Sciventions and are stabilized in sodium polyacrylate $(1.27 \mathrm{mg} / \mathrm{ml})$. The human cytokine array kit was from R\&D Systems. Matrigel and polycarbonate cell culture inserts $(8 \mu \mathrm{m}$ pore size $)$ were purchased from BD Biosciences. The protein assay kit (Bio-Rad DC; detergent compatible) was delivered by BioRad Laboratories as well as the enhanced chemiluminescence system (Clarity Western ECL Substrate). The monoclonal mouse antibody raised against human EMMPRIN was supplied by Merck. Polyclonal rabbit antibody raised against human VEGF was supplied by US Biological. The following secondary antibodies were used: polyclonal horseradish peroxidase (HRP)-conjugated goat anti-mouse IgG antibody (DAKO) and antirabbit igG antibody (Dianova).

\section{Cell culture}

The human astrocytoma cell line (MOG-G-CCM) was established from an anaplastic astrocytoma (grade III glioma) of normal adult brain. MOG-G-CCM were purchased from the European Collection of Authenticated Cell Cultures (ECACC; No. 86022702) and the cells were used at passages 6 to 38. Cryopreserved human umbilical vein endothelial cells (HUVEC); a widespread model for primary human endothelial cells (ECs) in the literature; were purchased from PromoCell (No. C-12200) and thawed as recommended by the manufacturer. They were cultivated in endothelial cell growth medium consisting of basal medium and supplements (PromoCell) on cell culture dishes. The cells were passaged according to the manufacturer's instructions having around $80-90 \%$ confluence and used at passages 3-6. The large $\mathrm{T}$ antigen carrying human microvascular endothelial cell line-1 (HMEC-1); retaining the morphologic; phenotypic; and functional characteristics of normal human microvascular endothelial cells [47] was purchased from American Type Culture Collection (ATCC ; CRL-3243). These immortalized cells are often used for many research studies as a replacement for primary human endothelial cells [48]. These immortalized endothelial cells were used at passages 3 to 30 .

\section{Cell viability}

The cytotoxicity of cerium oxide nanoparticles (CNPs) was measured by MTT [3-(4,5-Dimethylthiazol-2-yl)-2,5diphenyltetrazolium bromide] assay. The activity of mitochondrial dehydrogenases results in the formation of a purple formazan dye which serves as an indicator of cellular viability. After reaching the subconfluence (70-80\% confluence); HMEC-1; MOG-G-CCM; and HUVEC cells were treated with different concentrations of CNP up to $72 \mathrm{~h}$ in serum-free DMEM and endothelial basal medium; respectively. After CNP treatment the medium was removed; cells were washed with PBS and the MTT solution ( $0.5 \mathrm{mg} / \mathrm{ml}$ MTT in DMEM) was added to the cells. Thereafter; cells were lysed with dimethyl sulfoxide (DMSO) and the formazan formation was measured at $570 \mathrm{~nm}$. The results were shown as a percentage of mock-treated control which was set at $100 \%$.

\section{Preparation of conditioned medium}

The conditioned medium (CM) was obtained from MOG-G-CCM tumor cells $\left(\mathrm{CM}^{\mathrm{MOG}}\right)$. Briefly; MOG-G-CCM cells were seeded in $\varnothing 6$ $\mathrm{cm}$ culture dishes and grown to subconfluence (70-80\% confluence). The serum-containing medium was removed and after washing in phosphate-buffered saline (PBS) the cells were treated for $48 \mathrm{~h}$ either with $300 \mu \mathrm{M}$ CNP or without CNP (mock-treated control) in a serumfree high glucose DMEM. Afterwards this medium was removed and the cells were washed with PBS. To obtain conditioned medium containing the soluble factors released by the tumor cells; a further incubation for $48 \mathrm{~h}$ with $1.75 \mathrm{ml}$ serum-free high glucose DMEM was performed. Following this; conditioned medium of untreated $\left(\mathrm{CM}^{\mathrm{MOG}(-)}\right)$ or $\mathrm{CNP}-$ treated $\left(\mathrm{CM}^{\mathrm{MOG}(+)}\right)$ tumor cells was collected and freshly used or stored at $-20^{\circ} \mathrm{C}$. Same treatment was subjected to HMEC- 1 cells to obtain $\mathrm{CM}^{\mathrm{HMEC}(-)}$ or $\mathrm{CM}^{\mathrm{HMEC}(+)}$.

\section{Cell migration assay}

HMEC-1 were seeded in cell culture dishes and cultured until a confluence of $90-95 \%$ was reached. A $200 \mu$ filter tip was scratched across the bottom of the dish to produce a cell free area ("wound area") [49]. The detached cells were eliminated by washing the dishes twice with PBS. The attached cells were incubated with $300 \mu \mathrm{M} \mathrm{CNP}$ or mocktreated in DMEM containing $0.1 \%$ FCS or in the CM of untreated or CNP-treated MOG-G-CCM tumour cells. The "wound areas" were observed at $0 ; 24$ and $48 \mathrm{~h}$ and photographed under a microscope. Cell movement of HMEC-1 was determined by counting the cells which migrated into the cell free area. Each sample was analysed in triplicate and a total of three independent experiments was performed $(n=3)$.

\section{Invasion assay}

HMEC- 1 were seeded at a density of $5 \times 10^{4}$ in serum-free DMEM in the upper transwell culture chambers $(8 \mu \mathrm{m}$ pore size $)$ coated with Matrigel (BD Biosciences). $\mathrm{CM}^{\mathrm{MOG}(-)}$ or $\mathrm{CM}^{\mathrm{MOG}(+)}$ was used as chemoattractant. DMEM supplemented with $10 \%$ FCS was used as positive control. After $48 \mathrm{~h}$ incubation; the invaded cells on the lower membrane surface were fixed with methanol; stained with Coomassie Blue solution (0.05\% Coomassie Blue; $20 \% \mathrm{MeOH}$; $7.5 \%$ acetic acid) and counted under a microscope. Triplicates were conducted for each experiment and a total of three independent experiments was performed $(n=3)$.

\section{Tube formation assay}

Formation of capillary-like tubes of HMEC-1 was measured after 
$48 \mathrm{~h}$ treatment with CNP. A 96-well plate was coated with $60 \mu$ l growth factor-reduced Matrigel (BD Biosciences) per well and solidified for 45 minutes at $37^{\circ} \mathrm{C}$. HMEC- 1 were seeded at a density of $3 \times 10^{4}$ cells/ well in $100 \mu \mathrm{l}$ serum-free DMEM or in $100 \mu \mathrm{l}$ CM of untreated and CNP-treated MOG-G-CCM tumor cells. Plates were incubated at $37^{\circ} \mathrm{C}$ and $5 \% \mathrm{CO}_{2}$ for $7 \mathrm{~h}$; which was sufficient time for the formation of an intact network in the untreated control group; as was tested up-front to the experiments for this cell line. The formed network of tubes was recorded at a $5 \times$ magnification by the microscope and tubes forming intact networks were counted as described elsewhere [50]. Triplicates were conducted for each single experiment and a total of three experiments was performed $(n=3) .100 \mu M$ Thalidomide (SigmaAldrich) served as negative control.

\section{Detection of EMMPRIN and VEGF levels in supernatant and cell lysates}

The conditioned medium (CM) of mock-treated MOG-G-CCM $\left(\mathrm{CM}^{\mathrm{MOG}(-)}\right)$ and HMEC-1 $\left(\mathrm{CM}^{\mathrm{HMEC}(-)}\right)$ cells and CNP-treated tumor $\left(\mathrm{CM}^{\mathrm{MOG}(+)}\right)$ or endothelial cells $\left(\mathrm{CM}^{\mathrm{HMEC}(+)}\right)$ were prepared and collected as described. The CNP-induced modulations of various cytokines also involved in neoangiogenesis were determined in $500 \mu \mathrm{l}$ of $\mathrm{CM}$ using the Human XL Cytokine Array Kit from R\&D systems. The array was performed according to the manufacturer's protocol. Briefly; the nitrocellulose membranes spotted with the capture antibodies were incubated with CM overnight followed by incubation with a cocktail of biotinylated detection antibodies. Subsequently; a signal is generated at each capture spot corresponding to the amount of protein bound by applying streptavidin-HRP and chemiluminescent detection reagents.

SDS-PAGE was conducted according to the standard protocols published elsewhere [50] with minor modifications. After incubation; the cells were lysed in 1\% SDS with 1:1000 protease inhibitor cocktail (Sigma). After sonication; the protein concentration was measured by using a modified Lowry method (Bio-Rad DC). SDS-PAGE sample buffer (1.5M Tris-HCl pH 6.8; $6 \mathrm{~mL} \mathrm{20 \%} \mathrm{SDS;} 30 \mathrm{~mL}$ glycerol; $15 \mathrm{~mL}$ $\beta$-mercaptoethanol; and $1.8 \mathrm{mg}$ bromophenol blue) was added and after heating; the samples (20 $\mu \mathrm{g}$ total protein/lane) were applied to $10 \%(\mathrm{w} / \mathrm{v})$ SDS-polyacrylamide gels. After electroblotting; immunodetection was performed (1:1000 dilution of primary antibodies; 1:15000 dilution of secondary antibodies). Antigen-antibody complexes were visualized by an enhanced chemiluminescence system. GAPDH was used as internal control for equal loading.

\section{Statistical analysis}

Means were calculated from at least three independent experiments; unless otherwise stated and error bars represent the standard error of the mean (SEM). Analysis of statistical significance was performed by Student $t$ test or ANOVA with ${ }^{*} p \leq 0.05 ;{ }^{* *} p \leq 0.01$ and ${ }^{* * *} p \leq 0.001$ as levels of significance.

\section{Results}

\section{Cytotoxicity of cerium oxide nanoparticles on astrocytoma cells and endothelial cells}

The toxicity of conventional chemotherapeutics is not restricted to cancer cells; stromal cells are affected as well. Thus; a chemotherapeutic therapy is always associated with adverse side effects [51]. CNPs were shown to kill skin cancer cells; while being nontoxic to healthy cells; like fibroblasts $[52,53]$. In this study; the impact of CNP on human astrocytoma cells (MOG-G-CCM) and also healthy endothelial cells (HMEC-1 and HUVEC) was evaluated by using the MTT assay (Figure
1). CNP was shown to exert dose- and time-dependent cytotoxic effects on MOG-G-CCM cells (Figure 1A). After $72 \mathrm{~h}$ of incubation with 300 $\mu \mathrm{M}$ CNP the viability was decreased by $25 \%$ compared to the untreated control tumor cells which were set at $100 \%$. In contrast to the toxic impact of CNP on astrocytoma cells; the viability of healthy endothelial cells was even increased after treatment with the same concentrations. HMEC- 1 showed an increase in viability after $24 ; 48$ and $72 \mathrm{~h}$ treatment compared to the untreated control; which may be reflected by ongoing proliferation (Figure 1B). There was no toxicity observed even after 96

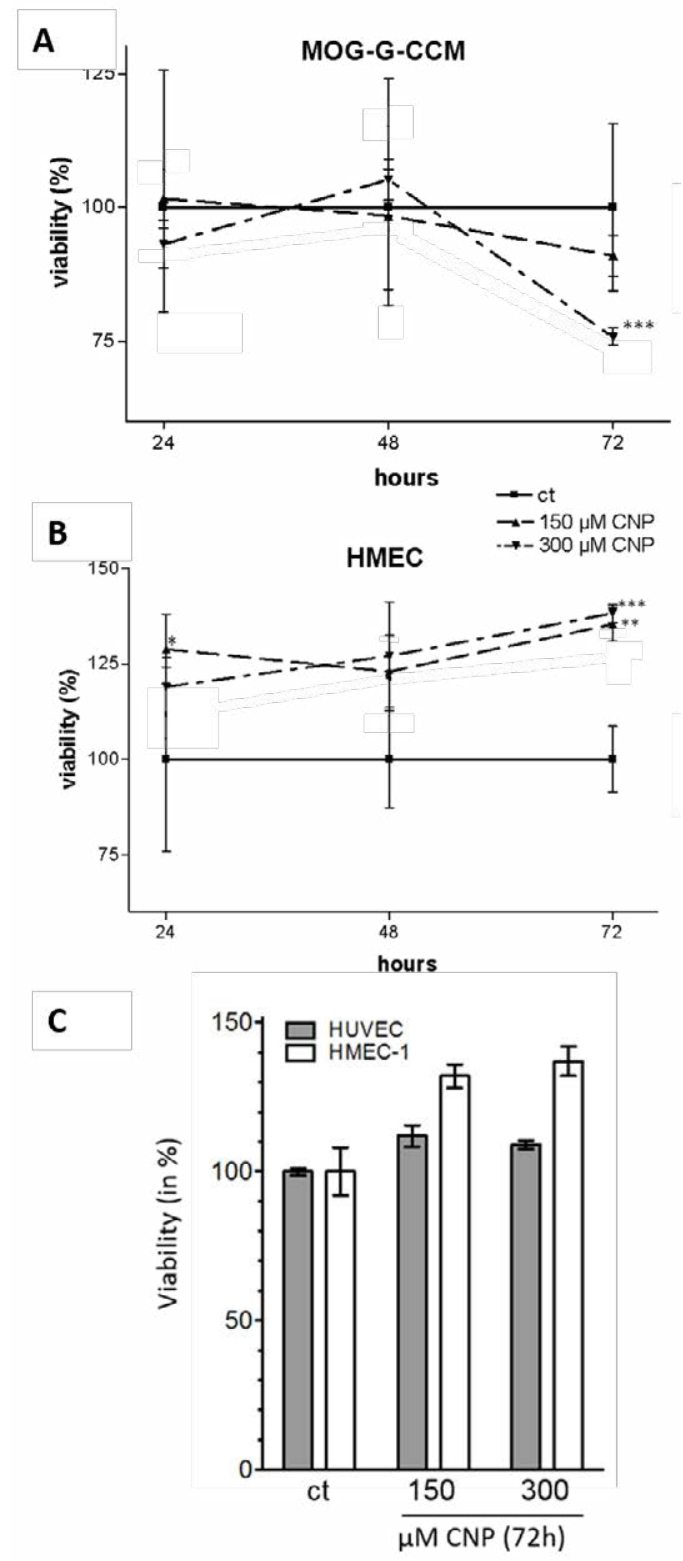

Figure 1: Cytotoxicity of CNP on tumor cells of the anaplastic astrozytoma MOG-G-CCM and healthy endothelial cells (HMEC-1 and HUVEC) Effects on cell viability were assessed by MTT assay. Tumor cells (MOG-G-CCM) (A) and human ECs (HMEC-1) (B) were incubated with 150 and $300 \mu \mathrm{M}$ CNP for 24, 48 and $72 \mathrm{~h}$. In $(\mathrm{C})$ the effects on cell viability of the immortalized endothelial cell line HMEC-1 and primary ECs (HUVEC) are compared after $72 \mathrm{~h}$ of incubation with 150 and $300 \mu \mathrm{M}$ CNP. The viability is shown as a percentage of untreated control (ct), which was set at $100 \%$. Data are presented as means \pm SEM of three independent experiments $(n=3) .{ }^{* * *} p<0.001,{ }^{* *} p<0.01,{ }^{*} p<0.05$ versus ct (Student's t-test). 
Citation: Sack-Zschauer M, Bader S, Brenneisen P (2017) Cerium Oxide Nanoparticles as Novel Tool in Glioma Treatment: An In vitro Study. J Nanomed Nanotechnol 8: 474. doi: 10.4172/2157-7439.1000474

Page 4 of 9

$\mathrm{h}$ of incubation with $500 \mu \mathrm{M}$ CNP (data not shown). In comparison to the immortalized endothelial cell line HMEC-1; the effects of CNP on cell viability were also tested in primary endothelial cells (HUVEC) after $72 \mathrm{~h}$ treatment (Figure $1 \mathrm{C}$ ). Also in these primary ECs no cytotoxic effects of CNP were observed. These data indicate that CNP exhibit a specific toxicity on tumor cells without harming healthy endothelial cells.

\section{Effect of cerium oxide nanoparticles on migration of endothelial cells}

Tumor cells exert an migratory effect on surrounding stromal cells. To determine whether CNP affect the migration of ECs; a "wound healing" scratch assay was performed (Figure 2). Therefore; $90 \%$ confluent HMEC-1 were incubated in $\mathrm{CM}$ of $\mathrm{CNP}$-treated $\left(\mathrm{CM}^{\mathrm{MOG}(+)}\right)$ or untreated $\left(\mathrm{CM}^{\mathrm{MOG}(-)}\right)$ tumor cells after scratching. The migration of endothelial cells incubated in the CM of CNP-treated tumor cells was significantly lowered by $40 \%$ after $48 \mathrm{~h}$ compared to the control in $\mathrm{CM}$ of untreated tumor cells. A CNP-pretreatment of endothelial cells before scratching did not lead to a stronger effect on EC migration.

\section{Effect of cerium oxide nanoparticles on invasion of} endothelial cells

Invasion of ECs into the tumor tissue; a crucial step in tumor angiogenesis; is mediated by the release of chemoattractive and matrix degrading proteins by the tumor cells. Therefore; the influence of CNP on EC invasion was investigated using transwell culture chambers (Figure 3). The $\mathrm{CM}$ of untreated $\left(\mathrm{CM}^{\mathrm{MOG}(-)}\right)$ and $\mathrm{CNP}$-treated tumor

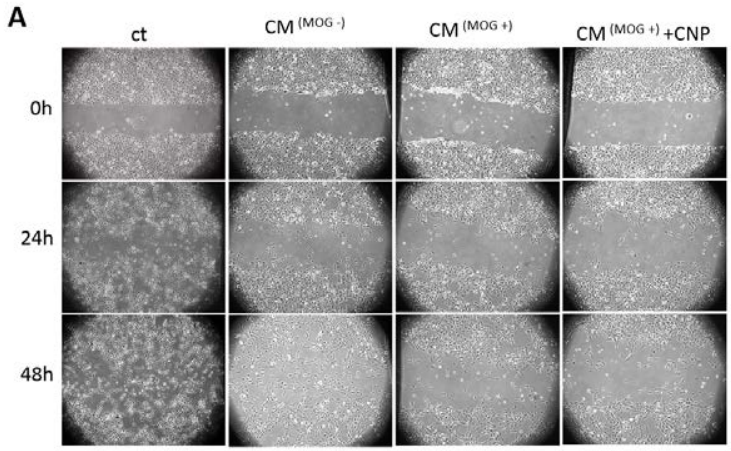

B

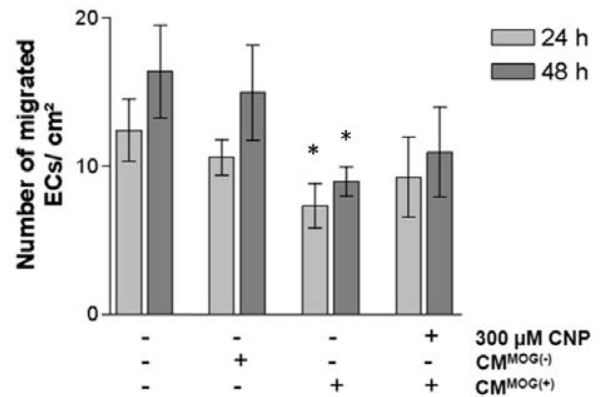

Figure 2: Effect of CNP on endothelial cell migration. The migration of ECs was assessed by performing a scratch assay. ECs were treated with $300 \mu \mathrm{M}$ $\mathrm{CNP}$ or incubated in conditioned medium of untreated $\left(\mathrm{CM}^{\mathrm{MOG}(-)}\right)$ or CNP-treated $\left(\mathrm{CM}^{\mathrm{MOG}(+)}\right)$ tumor cells. After 24 and $48 \mathrm{~h}$ the amount of migrated ECs into a cell free area ("wound area") was counted. Three independent experiments were performed $(n=3)$. Pictures of one representative experiment are presented $(A)$ and means \pm SEM of three independent experiments are shown (B). ${ }^{*} p<0.05$ versus ct (Student's t-test). cells $\left(\mathrm{CM}^{\mathrm{MOG}(+)}\right)$ served as chemoattractant. FCS-free culture media were used as negative control and culture media containing 10\% FCS served as positive control. The number of invaded ECs was significantly increased; when $\mathrm{CM}^{\mathrm{MOG}(-)}$ was used as chemoattractant containing proinvasive factors released by astrocytoma cells. When CM of CNPtreated tumor cells $\left(\mathrm{CM}^{\mathrm{MOG}(+)}\right)$ was used as chemoattractant; the number of invaded HMEC- 1 was significantly decreased by $61 \%$ compared to use of CM of untreated tumor cells; indicating an inhibitory effect of CNP on the release of pro-invasive signals in tumor cells. The antiinvasive effect was further enhanced by $87 \%$ after CNP-pretreatment of ECs before use in the assay (Figure 3). Finally these data showed that CNP exert anti-invasive effects on the interaction of astrocytoma and endothelial cells.

\section{Impact of cerium oxide nanoparticles on tube formation of ECs}

Angiogenesis includes the invasion of ECs into the tumor tissue but also the arrangement of new capillaries. To examine the impact of CNP on the ability to develop new capillaries; an in vitro tube formation assay was performed (Figure 4). Thalidomide served as negative control significantly decreasing the formation of tubular structures by $69 \%$ (A) compared to the untreated control (B). The data indicate an anti-angiogenic influence of CNP. Tube formation of ECs was slightly lowered by $25 \%$ when ECs were pretreated with $300 \mu \mathrm{M} \mathrm{CNP}$ for $48 \mathrm{~h}$ (C) compared to the untreated control (B). When ECs were seeded in $\mathrm{CM}$ of tumor cells $\left(\mathrm{CM}^{\mathrm{MOG}(-)}\right)(\mathrm{D})$; the formation of tubular structures increased compared to ECs; which were seeded in normal culture medium (B). Interestingly; this effect was reversed; when CM of CNP-treated tumor cells $\left(\mathrm{CM}^{\mathrm{MOG}(+)}\right)$ was used (E). The strongest decline in tube formation was observed; when $\left(\mathrm{CM}^{\mathrm{MOG}(+)}\right)$ was used and; additionally; ECs were treated with $300 \mu \mathrm{M}$ CNP before (F). Together; these data show an inhibitory effect of CNP on tube formation.

\section{Effect of cerium oxide nanoparticles on the expression and release of EMMPRIN and VEGF}

EMMPRIN is one of key player in neoangiogenesis and can be released by tumor cells and endothelial cells. Furthermore; during

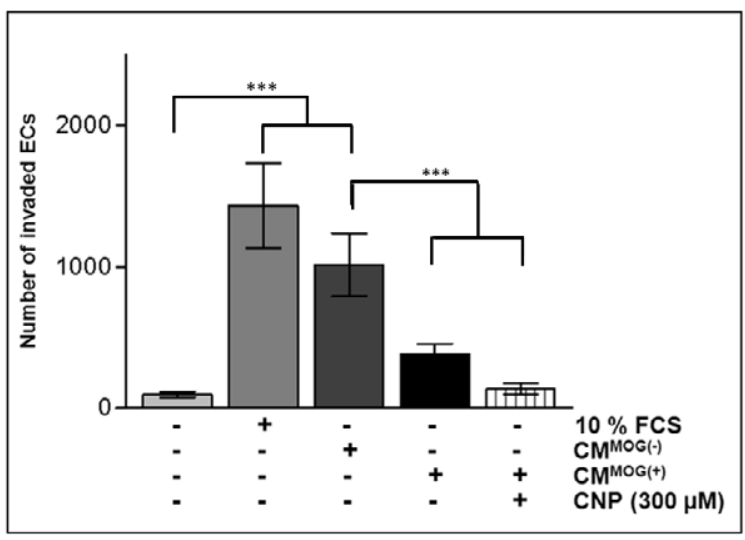

Figure 3: Effect of CNP on endothelial cell invasion. The invasive capacity of untreated and CNP-treated ECs (HMEC-1) was assessed using an invasion assay. Conditioned medium of untreated $\left(\mathrm{CM}^{\mathrm{MOG}(-)}\right)$ or CNP-treated tumor cells $\left(\mathrm{CM}^{\mathrm{MOG}(+)}\right)$ was used as chemoattractant. Cell culture medium containing $10 \%$ FCS served as positive control and serum-free culture medium served as negative control. After $48 \mathrm{~h}$ the invaded ECs were stained with Coomassie Blue and counted. Data are presented as means \pm SEM of three independent experiments. ${ }^{* * *} p<0.001,{ }^{* *} p<0.01,{ }^{*} p<0.05$ (ANOVA, Dunnett's test). 
Citation: Sack-Zschauer M, Bader S, Brenneisen P (2017) Cerium Oxide Nanoparticles as Novel Tool in Glioma Treatment: An In vitro Study. J Nanomed Nanotechnol 8: 474. doi: 10.4172/2157-7439.1000474

Page 5 of 9

tumor progression; the vascular epidermal growth factor VEGF is released by tumor cells to recruit ECs for neoangiogenesis [24]. To investigate; if EMMPRIN and VEGF might be responsible for the lowered migration; invasion and tube formation ability of ECs;
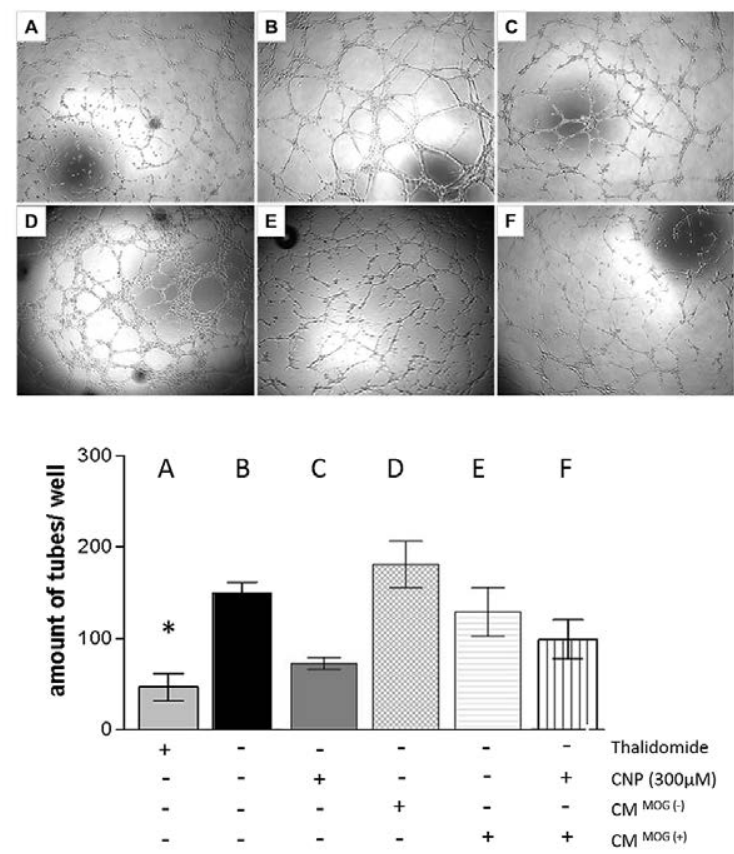

Figure 4: Effect of CNP on tube formation of endothelial cells. Tube formation HMEC-1 was assessed using an in vitro tube formation assay. ECs were pretreated with $300 \mu \mathrm{M}$ CNP for $48 \mathrm{~h}(\mathrm{C})$ or mock-treated (B) and placed in a 96-well plate containing $60 \mu \mathrm{l}$ of Matrigel/well. Thalidomide at a concentration of $100 \mu \mathrm{M}$ served as negative control (A). ECs were also seeded in conditioned medium of untreated $\left(\mathrm{CM}^{\mathrm{MOG}(-)}\right)(\mathrm{D})$ or CNP-treated astrocytoma cells $\left(\mathrm{CM}^{\mathrm{MOG}(+)}\right)$ (E). F shows the combined treatment, ECs were pretreated with CNP and seeded in $\mathrm{CM}$ of CNP-treated tumor cells $\left(\mathrm{CM}^{\mathrm{MOG}(+)}\right)$. Seven $\mathrm{h}$ after seeding, the amount of tubular structures was counted. Data are presented as means SEM of three independent experiments. ${ }^{*} p<0.05$ versus untreated control (B) (ANOVA).

\begin{tabular}{|cccc|}
\hline Protein & CMMOG(-) $^{\text {CMMOG(+) }}$ & $\begin{array}{c}\text { x-fold } \\
\text { change }\end{array}$ \\
\hline EMMPRIN & & $0.7 \pm 0.37$ \\
\hline ReferenzSpots & & & \\
\hline Protein & CM $^{\text {HMEC(-) }}$ & CM $^{\text {HMEC(+) }}$ & $\begin{array}{c}\text { x-fold } \\
\text { change }\end{array}$ \\
\hline EMMPRIN & & & $0.5 \pm 0.2$ \\
\hline ReferenzSpots & $\mathbf{O}$ & $\mathbf{O}$ & \\
\hline
\end{tabular}

Figure 5: Effect of CNP on extracellular matrix metalloproteinase inducer (EMMPRIN) of tumor cells and endothelial cells. ECs (HMEC-1) and astrocytoma cells (MOG-G-CCM) were treated for $48 \mathrm{~h}$ with $300 \mu \mathrm{M} \mathrm{CNP}\left(\mathrm{CM}^{(+)}\right)$ or mock-treated $\left(\mathrm{CM}^{(-)}\right)$. At the end of incubation, the medium was changed and after $48 \mathrm{~h}$ the conditioned medium of untreated $\left(\mathrm{CM}^{(-)}\right)$and CNP-treated cells $\left(\mathrm{CM}^{(+)}\right)$was collected. The amount of cytokines in the $\mathrm{CM}$ was assessed using a cytokine array. Data of tumor cells are presented as means \pm SEM of three independent experiments. Two independent experiments were performed with $\mathrm{CM}$ of HMEC. Data are shown as means \pm SEM versus mock-treated controls

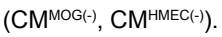

EMMPRIN and VEGF levels were determined in supernatant media (Figure 5) and in cell lysates (Figure 6).

In the supernatant of ECs and astrocytoma cells less EMMPRIN was detected; when cells were treated with $300 \mu \mathrm{M}$ for $48 \mathrm{~h}$ (Figure 5). Same effect was observed in cell lysates; here a CNP-mediated and time-dependent decrease of EMMPRIN levels was detected in ECs and tumor cells (Figure 6A and 6B). In addition; CNP treatment resulted in a decreased expression levels of VEGF in MOG-G-CCM tumor cells (Figure 6C).

A
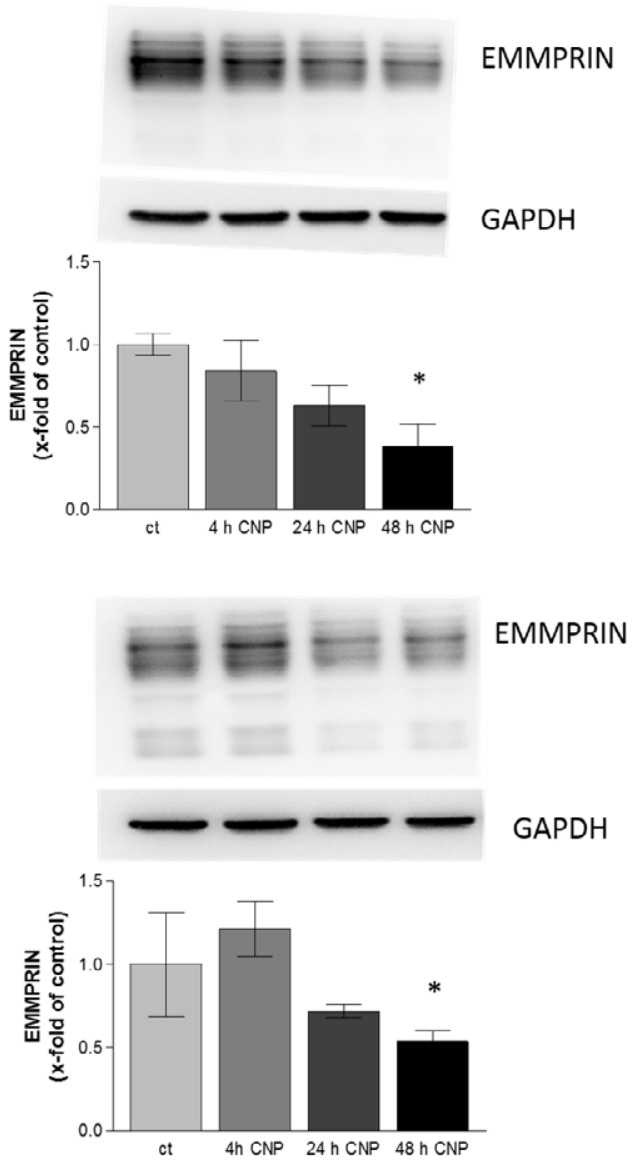

C

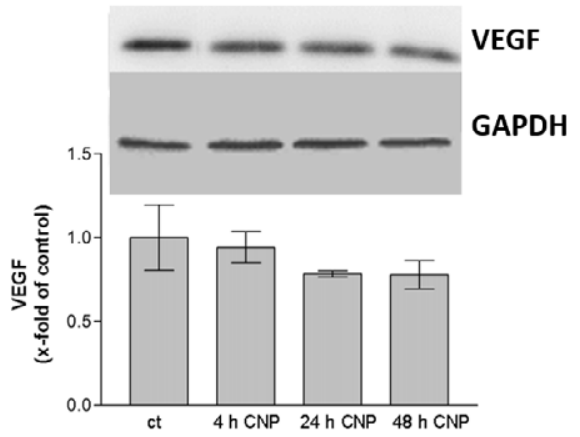

Figure 6: Effect of CNP on EMMPRIN and VEGF levels. HMEC-1 (A) and MOG-G-CCM (B, C) and were either mock-treated or incubated for 4, 24 and 48 $\mathrm{h}$ with $300 \mu \mathrm{M}$ CNP. Protein levels in cell lysates were evaluated by western blot analysis. GAPDH levels served as loading control. Data are presented as means \pm SEM of $(n=3)$ independent experiments for $(A)$ and $(B)$ and $(n=2)$ independent experiments for $(C){ }^{*} p<0.05$ versus mock-treated control (ct) (Student's t-test). 


\section{Discussion}

The successful chemotherapeutic treatment of malignant brain tumors such as gliomas represents one of the major challenges in oncology not least because of the blood-brain barrier (BBB); which limits or cancels passage of cytotoxic drugs $(\geq 600 \mathrm{kDa})$ to the site of the tumor [54]. However and in many cases; chemotherapy of those tumors is problematic; as the anticancer drugs are often hydrophobic molecules leading to restricted access to brain tissues [55]. Even though accompanied by severe side effects; a combination of surgery; radiotherapy and the use of chemotherapeutical drugs $[31,32,56]$ remain the main options in treatment of those tumors [57]. In that context; the alkylating prodrug temozolomide crosses the blood-brain barrier (BBB) and disintegrates spontanously (non-enzymatic) in methyl hydrazine which alkylates DNA bases finally resulting in inhibition of DNA replication and in triggering of cell death. The monoclonal antibody bevacizumab selectively binds to VEGF to prevent docking to its receptor and to inhibit angiogenic signals [58,59]. Nonetheless; longterm treatment with these drugs is often accompanied by hair loss; hematological and gastroenterological toxicities; and cholestatic hepatitis $[60,61]$. Dealing with the fact that resistances against these therapeutical compounds due to different molecular reasons have also been described over the years $[58,62,63]$; it seems reasonable to develop alternative or complementary therapies which are as effective as the traditional approaches but with less side effects. This is especially true considering that anaplastic astrocytoma and glioblastomas are among the most vascularized tumors and show a diffuse infiltrative growth resulting in an incomplete resection of the tumor mass and leading to recurrence [64]. For several years; nano-sized materials are in the focus as a promising therapeutical tool and offer ideal opportunities for targeted drug delivery $[65,66]$. Nanoparticles (ranging from 1-1000 $\mathrm{nm}$ in size) are intensively investigated particularly with regard to their carrier capacity and to drive them across the BBB to the tumor site. In addition to gold $(\mathrm{Au})$; lipids and proteins are main materials for many types of nanocarriers [39]. In that context; lipid nanoparticles or nanocapsules loaded with drugs like paclitaxel; are extensively investigated in the last few years [67]. In an interesting approach using a rat glioma model; the acidic tumor microenvironment caused by lactate efflux was exploited to transport $\mathrm{pH}$-sensitive doxorubicin (Dox)-loaded PEGylated-Au nanoparticles; where Dox is conjugated to Au-nanoparticles through an acid-labile hydrazone linker; to the tumor site resulting in rapid release of Dox at low pH [68]. However; prior to a clinical application of these nanocarriers; there are still some unanswered questions regarding the effectiveness in clinical studies; passive or active targeting; the optimal size; hydrophobicity and surface charge of the nanoparticles to efficiently cross the BBB; and potential side effects [3]. One of the rather novel approaches is the use of nanoparticles; which themselves exhibit an anti-cancer activity. In studies focusing on the putative use of cerium oxide nanoparticles (CNP; nanoceria) in therapies against neurodegenerative diseases it was found; that CNP (lower than $10 \mathrm{~nm}$ in size) were able to pass the $\mathrm{BBB}$ of rodents; where they prevented neuronal decay via an antioxidant activity based on their ability to switch between the two redox-states III and IV [69-71]. Based on that; we investigated in a simple in vitro tumorstroma model whether redox-active cerium oxide nanoparticles (CNP; nanoceria) with a mean size of about $4.7 \mathrm{~nm}$ diameter modulate cell toxicity and the invasive capacity of malignant glioma and endothelial cells (ECs). Finally; it was addressed whether CNP might be a suitable therapeutical tool to prevent neoangiogenesis in brain tumors. In the last years; an increasing number of articles deals with nanoceria being an antioxidant to detoxify reactive oxygen species (ROS) in different cells and tissues in vitro [72]. For example; nanoceria protect human dermal fibroblasts against a paraquat-initiated increase of the intracellular ROS level [73]. In other in vitro and in-vivo approaches; a bifunctional role of CNP in tumor-stroma interactions was shown; namely a prooxidative and cell killing function on squamous skin carcinoma and melanoma cells and with the same concentration an antioxidative and rather protecting function on stromal (healthy) fibroblasts and endothelial cells [43,52]. In addition; no adverse effects of nanoceria in healthy mice were observed [74]. Furthermore; recent studies with animal models show that cerium oxide nanoparticles cross the blood-brain barrier which opens a new therapeutical window in context of fighting brain diseases [71,75]. In our study; CNP was found to significantly induce cytotoxicity in astrocytoma cells in vitro; whereas the cell viability of endothelial HUVEC and HMEC-1 cells reflecting a stromal cell model was not decreased using identical concentrations. Furthermore; the migrative and invasive capacity of ECs was lowered after incubation in conditioned medium of CNP-treated astrocytoma cells as opposed to mock-treated tumor cells. Treatment with CNP of both cell types showed the maximum inhibitory effect on invasion of ECs. Furthermore; the effect of CNP on the ability of ECs to form capillary-like structures (=tube formation) being a crucial event in neovascularization; was assessed. When ECs were incubated in conditioned medium of astrocytoma cells; the amount of tubes increased; indicating the pro-angiogenic influence of astrocytoma cells on ECs in tumor-stroma interactions. This effect was reverted; when conditioned medium of CNP-treated astrocytoma was used in the assay. That data go in line with the in-vivo results of a former study; in which it was shown that CNP inhibit neovascularization in a melanoma xenograft model. Here the expression of CD31; which is one most widely used endothelial cell marker for studying angiogenesis and neovascularization; was significantly reduced (up to 60\%) in tumors of CNP treated mice compared to the control group [43]. In addition; an anti-angiogenic effect of CNP was described for ovarian cancer and agerelated macular degeneration by other research groups as well [76,77]; but to our knowledge nothing was described for glioma-endothelial cell interactions so far. As CNP impede migration; invasion and tube formation of ECs; our findings suggest an inhibition or decrease of the release of soluble (pro-invasive) factors by the studied cells. In our study; we focussed on the cell adhesion molecule EMMPRIN (CD147; Basigin) known to play a leading role in proliferation; invasion; and angiogenesis in brain tumors such as gliomas $[11,13]$. Indeed; further experiments showed that the amount of EMMPRIN in the conditioned medium of CNP-treated cells was significantly lowered compared to the mock-treated controls. In that context; it was shown earlier that EMMPRIN can be a target in anticancer therapies against gliomas. For example; the flavonoid icaritin from the herb Epimedium genus inhibited the invasion of the glioblastoma cell line U87MG by targeting EMMPRIN via the PTEN/Akt/HIF-1alpha pathway [78]. Furthermore; the invasion of the glioblastoma cell line U251 was inhibited by antisense RNA of EMMPRIN [79]. In malignant melanomas; EMMPRIN repression resulted in decreased VEGF production and lowered invasive capacity of the tumor cells [20]. VEGF expression was also lowered in our study. Albeit our data are a first indication that EMMPRIN is a potential target for cerium oxide nanoparticles in anticancer therapies; further studies have to be done to substantiate that hypothesis.

Together; our study shows an anti-invasive and anti-angiogenic effect of CNP in an in vitro astrocytoma-endothelial cell model; which is mediated by lowering the capacity of ECs to migrate; invade and to form new capillaries accompanied by inhibition of the release of EMMPRIN 
Additionally; CNP were found to kill a portion of astrocytoma cells; while being not toxic on ECs. An ideal cancer therapy should aim to destroy cancer cells and to prevent pro-tumoral processes like invasion and neoangiogenesis; while not harming healthy stromal cells. In that context; CNP may be a good candidate for an effective therapy with less side effects; due to their selective cytotoxicity on tumor cells. An advantage of the use of CNP over a pure anti-angiogenic therapeutic approach is that CNP not only targets neoangiogenesis but also kills tumor cells via pro-oxidative mechanisms leading to apoptosis [43,52]. In conclusion; this study shows promising effects of CNP for a potential use as therapeutical tool in the treatment of malignant glioma. It was already shown that CNP being effective in treatment of neurodegenerative diseases [69,71]. Also; a combinational approach of CNP with; for example; other anti-angiogenic compounds is conceivable. In that context; a combination of the VEGF inhibitor cediranib and the JAK/STAT3 inhibitor AZD1480 decreased tumor volume and vasculature in a glioblastoma mouse model [36]. Additionally; a combination of CNP treatment and radiation therapy was shown to sensitize the breast carcinoma cell line MCF-7 to radiation on the one hand; but also protect normal breast CRL8798 epithelial cells from radiation-induced damage on the other [53]. Further on; we could show earlier that a combination of doxorubicin with CNP enhances the antitumor activity of doxorubicin in human melanoma cells; but do not cause DNA damage and even protect human dermal fibroblasts from doxorubicin-induced cytotoxicity [80]. This study shows for the first time that cerium oxide nanoparticles with a diameter of smaller than $10 \mathrm{~nm}$ and not used as nanocarriers may be a valuable and efficient tool to attack and kill malignant glioma cells and to protect normal (healthy) cells from the detrimental influence of tumor cells.

\section{Acknowledgments}

The authors thank C. Wyrich for excellent technical assistance.

\section{References}

1. Siegel RL, Miller KD, Jemal A (2016) Cancer statistics, 2016. CA Cancer J Clin 66: 7-30.

2. Fisher JL, Schwartzbaum JA, Wrensch M, Wiemels JL (2007) Epidemiology of brain tumors. Neurol Clin 25: 867-890.

3. Pinto MP, Arce M, Yameen B, Vilos C (2017) Targeted brain delivery nanoparticles for malignant gliomas. Nanomedicine 12: 59-72.

4. Khasraw M, Ameratunga M, Grommes C (2014) Bevacizumab for the treatment of high-grade glioma: an update after phase III trials. Expert Opin Biol Ther 14: 729-740

5. Tonn JC, Goldbrunner R (2003) Mechanisms of glioma cell invasion. Acta Neurochir Suppl 88: 163-167.

6. Liotta LA, Kohn EC (2001) The microenvironment of the tumour-host interface. Nature 411: 375-379.

7. Carmeliet $P$, Jain RK (2000) Angiogenesis in cancer other diseases. Nature 407: 249-257.

8. Folkman J (1972) Anti-angiogenesis: new concept for therapy of solid tumors. Ann Surg 175: 409-416.

9. Louis DN, Perry A, Reifenberger G, von Deimling A, Figarella-Branger D, et al. (2016) The 2016 World Health Organization Classification of Tumors of the Central Nervous System: a summary. Acta Neuropathol 131: 803-820

10. Yu XL, Hu T, Du JM, Ding JP, Yang XM, et al. (2008) Crystal structure of HAb18G/CD147: implications for immunoglobulin superfamily homophilic adhesion. J Biol Chem 283: 18056-18065.

11. Yin H, Shao Y, Chen $X$ (2017) The effects of CD147 on the cell proliferation, apoptosis, invasion, angiogenesis in glioma. Neurol Sci 38: 129-136.

12. Tsai WC, Chen Y, Huang LC, Lee HS, Ma HI, et al. (2013) EMMPRIN expression positively correlates with $\mathrm{WHO}$ grades of astrocytomas meningiomas. J Neurooncol 114: 281-290.

13. Tian L, Zhang $Y$, Chen $Y$, Cai M, Dong $H$, et al. (2013) EMMPRIN is an independent negative prognostic factor for patients with astrocytic glioma. PLoS one 8: e58069.

14. Milia-Argeiti E, Mourah S, Vallee B, Huet E, Karamanos NK, et al. (2014) EMMPRIN/CD147-encriched membrane vesicles released from malignant human testicular germ cells increase MMP production through tumor-stroma interaction. Biochim Biophys Acta 1840: 2581-2588.

15. Redzic JS, Kendrick AA, Bahmed K, Dahl KD, Pearson CG, et al. (2013) Extracellular vesicles secreted from cancer cell lines stimulate secretion of MMP-9, IL-6, TGF-beta1 EMMPRIN. PloS one 8: e71225.

16. Agrawal SM, Yong VW (2011) The many faces of EMMPRIN - roles in neuroinflammation. Biochim Biophys Acta 1812: 213-219.

17. Abu El-Asrar AM, Ahmad A, Alam K, Siddiquei MM, Mohammad G, et al (2017) Extracellular matrix metalloproteinase inducer (EMMPRIN) is a potential biomarker of angiogenesis in proliferative diabetic retinopathy. Acta Ophthalmol 95: 697-704.

18. Chen Y, Zhang H, Gou X, Horikawa Y, Xing J, et al. (2009) Upregulation of HAb18G/CD147 in activated human umbilical vein endothelial cells enhances the angiogenesis. Cancer letters 278: 113-121.

19. Sameshima T, Nabeshima K, Toole BP, Inoue T, Yokogami K, et al. (2003) Correlation of emmprin expression in vascular endothelial cells with bloodbrain-barrier function: a study using magnetic resonance imaging enhanced by Gd-DTPA immunohistochemistry in brain tumors. Virchows Arch 442: 577-584

20. Hu X, Su J, Zhou Y, Xie X, Peng C, et al. (2017) Repressing CD147 is a nove therapeutic strategy for malignant melanoma. Oncotarget 8: 25806-25813.

21. Guo H, Li R, Zucker S, Toole BP (2000) EMMPRIN (CD147), an inducer of matrix metalloproteinase synthesis, also binds interstitial collagenase to the tumor cell surface. Cancer Res 60: 888-891.

22. Marchiq I, Albrengues J, Granja S, Gaggioli C, Pouyssegur J, et al. (2015) Knock out of the BASIGIN/CD147 chaperone of lactate/H+ symporters disproves its pro-tumour action via extracellular matrix metalloproteases (MMPs) induction Oncotarget 6: 24636-24648.

23. Fei F, Li S, Fei Z, Chen Z (2015) The roles of CD147 in the progression of gliomas. Expert Rev Anticancer Ther 15: 1351-1359.

24. Hundsberger T, Reardon DA, Wen PY (2017) Angiogenesis inhibitors in tackling recurrent glioblastoma. Expert Rev Anticancer Ther 17: 507-515.

25. Weathers SP, de Groot J (2015) VEGF Manipulation in Glioblastoma. Oncology (Williston Park) 29: 720-727.

26. Jia L, Wang H, Qu S, Miao X, Zhang J (2008) CD147 regulates vascular endothelial growth factor-A expression, tumorigenicity, chemosensitivity to curcumin in hepatocellular carcinoma. IUBMB Life 60: 57-63.

27. Chen Y, Peng J, Han M, Omar M, Hu D, et al. (2015) A low-molecularweight heparin-coated doxorubicin-liposome for the prevention of melanoma metastasis. J Drug Target 23: 335-346.

28. Edwardson DW, Narendrula R, Chewchuk S, Mispel-Beyer K, Mapletoft JP et al. (2015) Role of Drug Metabolism in the Cytotoxicity Clinical Efficacy of Anthracyclines. Curr Drug Metab 16: 412-426.

29. Arvold ND, Reardon DA (2014) Treatment options outcomes for glioblastoma in the elderly patient. Clin Interv Aging 9: 357-367.

30. Birk HS, Han SJ, Butowski NA (2017) Treatment options for recurrent highgrade gliomas. CNS Oncol 6: 61-70.

31. Delgado-Lopez PD, Corrales-Garcia EM (2016) Survival in glioblastoma: review on the impact of treatment modalities. Clin Tranl Oncol 18: 1062-1071.

32. Perry JR, Laperriere N, Mason WP (2017) Radiation plus Temozolomide in Patients with Glioblastoma. N Engl J Med 376: 2197

33. Yan Y, Xu Z, Dai S, Qian L, Sun L, et al. (2016) Targeting autophagy to sensitive glioma to temozolomide treatment. J Exp Clin Cancer Res 35: 23.

34. Hegi ME, Diserens AC, Gorlia T, Hamou MF, de Tribolet N, et al. (2005) MGMT gene silencing benefit from temozolomide in glioblastoma. N Engl J Med 352 997-1003.

35. Curry RC, Dahiya S, Alva Venur V, Raizer JJ, Ahluwalia MS (2015) Bevacizumab 
Citation: Sack-Zschauer M, Bader S, Brenneisen P (2017) Cerium Oxide Nanoparticles as Novel Tool in Glioma Treatment: An In vitro Study. J Nanomed Nanotechnol 8: 474. doi: 10.4172/2157-7439.1000474

Page 8 of 9

in high-grade gliomas: past, present, future. Expert Rev Anticancer Ther 15 387-397.

36. de Groot JF, Mandel JJ (2014) Update on anti-angiogenic treatment for malignant gliomas. Curr Oncol Rep 16: 380.

37. Schroeder A, Heller DA, Winslow MM, Dahlman JE, Pratt GW, et al. (2011) Treating metastatic cancer with nanotechnology. Nat Rev Cancer 12: 39-50.

38. Jain KK (2008) Nanomedicine: application of nanobiotechnology in medica practice. Med Princ Pract 17: 89-101.

39. Frosina G (2016) Nanoparticle-mediated drug delivery to high-grade gliomas. Nanomedicine 12: 1083-1093.

40. Wei X, Chen X, Ying M, Lu W (2014) Brain tumor-targeted drug delivery strategies. Acta Pharm Sin B 4: 193-201.

41. Pesic M, Podolski-Renic A, Stojkovic S, Matovic B, Zmejkoski D, et al. (2015) Anti-cancer effects of cerium oxide nanoparticles its intracellular redox activity. Chem Biol Interact 232: 85-93.

42. Das S, Dowding JM, Klump KE, McGinnis JF, Self W, et al. (2013) Cerium oxide nanoparticles: applications prospects in nanomedicine. Nanomedicine 8 : 1483-1508.

43. Alili L, Sack M, von Montfort C, Giri S, Das S, et al. (2013) Downregulation of tumor growth invasion by redox-active nanoparticles. Antioxid Redox Signal 19: $765-778$

44. Karakoti A, Singh S, Dowding JM, Seal S, Self WT (2010) Redox-active radical scavenging nanomaterials. Chem Soc Rev 39: 4422-4432.

45. Zhang X, Liu L, Liu J, Cheng Z, Wang Z, et al. (2017) Endothelial cells cocultured with renal carcinoma cells significantly reduce RECK expression under chemical hypoxia. Cell Biol Int 41: 922-927.

46. Buchanan CF, Szot CS, Wilson TD, Akman S, Metheny-Barlow LJ, et al. (2012) Cross-talk between endothelial breast cancer cells regulates reciprocal expression of angiogenic factors in vitro. J Cell Biochem 113: 1142-1151.

47. Ades EW, Candal FJ, Swerlick RA, George VG, Summers S, et al. (1992) HMEC-1: establishment of an immortalized human microvascular endothelial cell line. J Invest Dermatol 99: 683-690.

48. Kenig S, Alonso MB, Mueller MM, Lah TT (2010) Glioblastoma endothelia cells cross-talk, mediated by SDF-1, enhances tumour invasion endothelial proliferation by increasing expression of cathepsins B, S, MMP-9. Cancer Let 289: 53-61.

49. Liang CC, Park AY, Guan JL (2007) In vitro scratch assay: a convenien inexpensive method for analysis of cell migration in vitro. Nat Protoc 2: 329 333

50. Laemmli UK (1970) Cleavage of structural proteins during the assembly of the head of bacteriophage T4. Nature 227: 680-685.

51. Perrino C, Schiattarella GG, Magliulo F, Ilardi F, Carotenuto G, et al. (2014) Cardiac side effects of chemotherapy: state of art strategies for a correct management. Curr Vasc Pharmaocol 12: 106-116.

52. Alili L, Sack M, Karakoti AS, Teuber S, Puschmann K, et al. (2011) Combined cytotoxic anti-invasive properties of redox-active nanoparticles in tumor-stroma interactions. Biomaterials 32: 2918-2929.

53. Tarnuzzer RW, Colon J, Patil S, Seal S (2005) Vacancy engineered ceria nanostructures for protection from radiation-induced cellular damage. Nano letters 5: 2573-2577.

54. Benny O, Pakneshan P (2009) Novel technologies for antiangiogenic drug delivery in the brain. Cell Adh Migr 3: 224-229.

55. Drapeau A, Fortin D (2015) Chemotherapy Delivery Strategies to the Centra Nervous System: neither Optional nor Superfluous. Curr Cancer Drug Targets 15: $752-768$

56. Altieri R, Zenga F, Fontanella MM, Cofano F, Agnoletti A, et al. (2015) Glioma Surgery: Technological Advances to Achieve a Maximal Safe Resection. Surg Technol Int 27: 297-302.

57. Rajesh Y, Pal I, Banik P, Chakraborty S, Borkar SA, et al. (2017) Insights into molecular therapy of glioma: current challenges next generation blueprint. Acta pharmacologica Sinica 38: 591-613.

58. Tamura R, Tanaka T, Miyake K, Yoshida K, Sasaki H (2017) Bevacizumab for malignant gliomas: current indications, mechanisms of action resistance, markers of response. Brain Tumor Pathol 34: 62-77.

59. Niyazi M, Harter PN, Hattingen E, Rottler M, von Baumgarten L, et al. (2016) Bevacizumab radiotherapy for the treatment of glioblastoma: brothers in arms or unholy alliance? Oncotarget 7: 2313-2328.

60. Wang Y, Kong X, Guo Y, Wang R, Ma W (2017) Continuous dose-intense temozolomide cisplatin in recurrent glioblastoma patients. Medicine (Baltimore) 96: e6261.

61. Watanabe S, Kuwabara Y, Suehiro S, Yamashita D, Tanaka M, et al. (2017) Valproic acid reduces hair loss improves survival in patients receiving temozolomide-based radiation therapy for high-grade glioma. Eur $\mathrm{J}$ Clin Pharmacol 73: 357-363.

62. Atkins RJ, Ng W, Stylli SS, Hovens CM, Kaye AH (2015) Repair mechanisms help glioblastoma resist treatment. J Clin Neurosci 22: 14-20.

63. Zhang J, Stevens MF, Bradshaw TD (2012) Temozolomide: mechanisms of action, repair resistance. Curr Mol Pharmacol 5: 102-114.

64. Davis ME (2016) Glioblastoma: Overview of Disease Treatment. Clin J Oncol Nurs 20: S2-8.

65. Raudino G, Caffo M, Caruso G, Alafaci C, Tomasello F (2011) Nanoparticlebased cerebral drug-delivery systems antiangiogenic approach in gliomas treatment. Recent Pat Nanotechnol 5: 239-244.

66. Caruso G, Caffo M, Alafaci C, Raudino G, Cafarella D, et al. (2011) Could nanoparticle systems have a role in the treatment of cerebral gliomas? Nanomedicine 7: 744-752

67. Bhujbal SV, de Vos P, Niclou SP (2014) Drug cell encapsulation: alternative delivery options for the treatment of malignant brain tumors. Adv Drug Deliv Rev 67-68: 142-153.

68. Cheng Y, Dai Q, Morshed RA, Fan X, Wegscheid ML, et al. (2014) Bloodbrain barrier permeable gold nanoparticles: an efficient delivery platform for enhanced malignant glioma therapy imaging. Small 10: 5137-5150.

69. Naz S, Beach J, Heckert B, Tummala T, Pashchenko O, et al. (2017) Cerium oxide nanoparticles: a 'radical' approach to neurodegenerative disease treatment. Nanomedicine 12: 545-553.

70. Arya A, Gangwar A, Singh SK, Roy M, Das M, et al. (2016) Cerium oxide nanoparticles promote neurogenesis abrogate hypoxia-induced memory impairment through AMPK-PKC-CBP signaling cascade. Int J Nanomed 11 : 1159-1173.

71. Heckman KL, DeCoteau W, Estevez A, Reed KJ, Costanzo W, et al. (2013) Custom cerium oxide nanoparticles protect against a free radical mediated autoimmune degenerative disease in the brain. ACS nano 7: 10582-10596.

72. Walkey C, Das S, Seal S, Erlichman J, Heckman K, et al. (2015) Catalytic Properties Biomedical Applications of Cerium Oxide Nanoparticles. Environ Sci Nano 2: 33-53.

73. von Montfort C, Alili L, Teuber-Hanselmann S, Brenneisen P (2015) Redoxactive cerium oxide nanoparticles protect human dermal fibroblasts from PQinduced damage. Redox Biol 4: 1-5.

74. Hirst SM, Karakoti A, Singh S, Self W, Tyler R, et al. (2013) Bio-distribution in vivo antioxidant effects of cerium oxide nanoparticles in mice. Environ Toxicol 28: 107-118.

75. Bailey ZS, Nilson E, Bates JA, Oyalowo A, Hockey KS, et al. (2016) Cerium Oxide Nanoparticles Improve Outcome After In Vitro In Vivo Mild Traumatic Brain Injury. J Neurotrauma.

76. Giri S, Karakoti A, Graham RP, Maguire JL, Reilly CM, et al. (2013) Nanoceria: a rare-earth nanoparticle as a novel anti-angiogenic therapeutic agent in ovarian cancer. PloS one 8: e54578.

77. Kyosseva SV, Chen L, Seal S, McGinnis JF (2013) Nanoceria inhibit expression of genes associated with inflammation angiogenesis in the retina of Vldlr null mice. Exp Eye Res 116: 63-74

78. Xu B, Jiang C, Han H, Liu H, Tang M, et al. (2015) Icaritin inhibits the invasion epithelial-to-mesenchymal transition of glioblastoma cells by targeting EMMPRIN via PTEN/AKt/HIF-1alpha signalling. Clin Exp Pharmacol Physiol 42: $1296-1307$. 
Citation: Sack-Zschauer M, Bader S, Brenneisen P (2017) Cerium Oxide Nanoparticles as Novel Tool in Glioma Treatment: An In vitro Study. J Nanomed Nanotechnol 8: 474. doi: 10.4172/2157-7439.1000474

Page 9 of 9

79. Liang Q, Xiong H, Gao G, Xiong K, Wang X, et al. (2005) Inhibition of basigin expression in glioblastoma cell line via antisense RNA reduces tumor cell invasion angiogenesis. Cancer Biol Ther 4: 759-762.
80. Sack M, Alili L, Karaman E, Das S, Gupta A, et al. (2014) Combination of conventional chemotherapeutics with redox-active cerium oxide nanoparticles-a novel aspect in cancer therapy. Mol Cancer Ther 13: 1740-1749. 